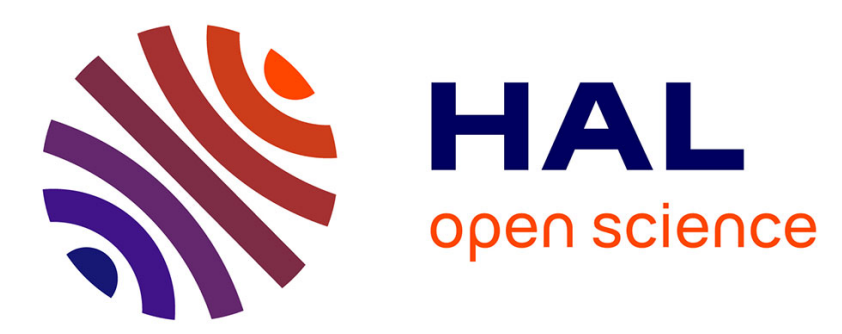

\title{
An integrated sample-in-answer-out microfluidic chip for rapid human identification by STR analysis
}

Delphine Le Roux, Brian E. Root, Jeffrey A. Hickey, Orion N. Scott, Anchi

Tsuei, Jingyi Li, David J. Saul, Luc Chassagne, James P. Landers, Philippe de Mazancourt

\section{To cite this version:}

Delphine Le Roux, Brian E. Root, Jeffrey A. Hickey, Orion N. Scott, Anchi Tsuei, et al.. An integrated sample-in-answer-out microfluidic chip for rapid human identification by STR analysis. Lab on a Chip, 2014, 14, pp.4415-4425. 10.1039/c4lc00685b . hal-01120976

\section{HAL Id: hal-01120976 https://hal.science/hal-01120976}

Submitted on 24 Sep 2015

HAL is a multi-disciplinary open access archive for the deposit and dissemination of scientific research documents, whether they are published or not. The documents may come from teaching and research institutions in France or abroad, or from public or private research centers.
L'archive ouverte pluridisciplinaire HAL, est destinée au dépôt et à la diffusion de documents scientifiques de niveau recherche, publiés ou non, émanant des établissements d'enseignement et de recherche français ou étrangers, des laboratoires publics ou privés. 
For submission to Lab Chip

\section{Integrated sample-in-answer-out microfluidic chip for Rapid Human Identification by STR analysis ${ }^{\dagger}$}

Delphine Le Roux, ${ }^{a} *$ Brian E. Root, ${ }^{b} *$ Jeff Hickey, ${ }^{b}$ Orion N. Scott, ${ }^{b}$ Anchi Tsuei, ${ }^{b}$ Jingyi Li, $^{b}$ David Saul, ${ }^{c}$ Luc Chassagne, ${ }^{a}$ James P. Landers, ${ }^{d}$ Philippe de Mazancourt ${ }^{\mathrm{a} \ddagger}$

$* \star$ These authors contributed equally to this work

${ }^{\mathrm{a}}$ University of Versailles-Saint Quentin en Yvelines, 55 Avenue de Paris, 78000 Versailles, France

${ }^{\text {b} M i c r o L a b ~ D i a g n o s t i c s, ~ I n c, ~ 705 D ~ D a l e ~ A v e, ~ C h a r l o t t e s v i l l e, ~ V A ~ 22903, ~ U S A ~}$

'ZyGEM Corporation Ltd, Waikato Innovation Park, Ruakura Road, Hamilton 3216 Aotearoa, New Zealand

${ }^{\mathrm{d}}$ Department of Mechanical Engineering, University of Virginia, Engineer's Way, Charlottesville, VA 22904, USA

${ }^{\dagger}$ Electronic supplementary information (ESI) available: microfluidic chip fabrication, sample collection, analytical processes inside the microfluidic chip, conventional analysis, data analysis and supplementary figures. 


\section{Introduction}

Over the past decades, extensive research has gone into the development of micro-total analysis systems ( $\mu$-TAS) in genetic analysis and diagnostics ${ }^{1-6}$. Microfluidics offer a large number of advantages for rapidly analyzing samples because several steps commonly performed in different benchtop instruments can be integrated into a single microfluidic device - commonly called labon-a-chip devices ${ }^{7}$. The entire sample processing often encompasses (1) sample collection and treatment to release the target of interest (e.g., bacteria, DNA, proteins, cell), (2) amplification of the target and (3) detection and interpretation of this amplification product to get the result of the assay. Many of these benchtop processes have been independently demonstrated on microfluidic chips $^{8-11}$. When performed in a conventional laboratory, these steps require trained technicians to transfer the samples to the instruments performing each of the different steps and are frequently performed in batches that lead to a long turnaround time. Additionally, current benchtop analytical processes are often long, and contamination can occur because samples are transferred from one tube to another between steps. Some efforts have been made to try to automate the bentchop processes ${ }^{12}$, but microfluidic devices may offer a greater possibility of faster sub-assay times and automated integration of multiple processes. However, realizing this vision of integrating multiple steps has been challenging, especially when it comes to integrating the sample preparation ${ }^{13,14}$.

Demonstrations of integrated microfluidic analysis systems have varied widely in terms of the

target and in the analytical detection method (e.g., qPCR, electrophoresis, colorimetric, etc). ${ }^{15-24}$ Some genetic assays currently require an electrophoretic separation as the assay output. One such assay requiring electrophoretic separation is forensic short-tandem repeat (STR) analysis for 
human identification. ${ }^{25}$ This assay is particularly challenging for integrated microfluidics as it has very stringent requirements and requires at least three analytical steps: (1) DNA preparation from the sample, (2) DNA amplification, and (3) DNA separation with multicolour fluorescence detection. ${ }^{26}$ Often, the reagents used for one of these steps is incompatible or detrimental to downstream processes which further increases the complexity of the microfluidic architecture in order to isolate any incompatible reagents ${ }^{27}$.

The first demonstration of a sample-in-answer-out microfluidic chip for genetic analysis by Easley et $a .^{27}$ detected B. anthracis from blood by solid phase extraction, PCR, and electrophoretic separation. However, several limitations of this system, such as single-color detection and separation resolution, make it non-applicable for STR analysis. Liu et $a .^{28}$ expanded on this work to demonstrate an integrated microchip for STR analysis. While the level of assay integration is significant, the complex microchip is manufactured from glass and requires pre-treatment of the channel (e.g., polymer coating the separation channel), which make this approach prohibitively expensive for widespread use.

Other systems have been demonstrated in recent years, each with advantages and limitations. Two groups working toward point-of-collection STR analysis demonstrated end-to-end analysis, but with the electrophoretic separation performed either on a separate separation microchip, or a capillary $^{29,30}$. This arrangement results in multiple consumable components and begins to move away from the goal of developing true $\mu$ TAS systems. Another demonstration of an integrated chip required a relatively large footprint $(296 \mathrm{~mm} \mathrm{x} 166 \mathrm{~mm})$ with the device being a multicomponent structure connected together ${ }^{31}$. The result is a bulky consumable that requires complex and expensive manufacturing. While each of these systems represents a significant 
advance for STR analysis, taken together, their limitations demonstrate the challenge of creating a compact, low-cost, fully integrated disposable microchip for this type of assay.

Here, we report on the development of an integrated microfluidic chip for "sample in-answerout" human identification that is a single injection- molded piece approximately the size of a 96 well plate with simple, low-cost fabrication. The compact size of the device is achieved by a direct DNA extraction without any washing steps by using the protease from Bacillus sp. Erebus Antarctica 1 (EA1) $)^{32,33}$, a small PCR chamber heated by an IR laser $^{34}$ and a $7 \mathrm{~cm}$ microchannel capillary for DNA separation permitted by the use of a proprietary polymer. Moreover, the microfluidic chip is completely contained: no liquids leave the microchip during the assay and the instrument is not touched by liquid so contamination risks are minimized. The extracted DNA and amplified products are easily recoverable for conventional post-assay analysis if desired. The total assay time is reduced to almost 2 hours compared to the conventional processes in a forensic laboratory of up to 10 hours.

The instrument associated with the microfluidic chip contains the associated hardware to perform fluid flow control and each of the molecular assays that occur within the microchip. The chip contains no active, functional features. In this paper, we report the development and demonstration of each sub-assay inside the microfluidic chip (Liquid Extraction (LE), Powerplex ${ }^{\circledR} 18$ Fast System PCR and Microchip Electrophoresis (ME)) as well as the integration of two of the sub-assays together (for buccal swabs and FTA paper DNA inputs) to finally achieve the full integration of the process. The full functionality of the integrated microchip and instrument is demonstrated showing for the first time that a low cost and manufacturablecomplete micro-total analysis system is able to generate a full genetic profile in about two hours. 


\section{Methods and experimental section}

\subsection{Instrument design}

Fig. 1a shows the instrument that drives the analysis within the microfluidic chip. The instrument has been designed in parallel with the microfluidic chip (shown in Fig. 1b), thereby ensuring effective control of the microfluidic movements and the different molecular assays for STR analysis. The main features interacting with the microfluidic chip are located within a portion of the instrument called the Chip Interface Module (CIM). The CIM is designed to receive the microfluidic chip with the sample acceptors attached (Fig. 1b) with a precision of $100 \mu \mathrm{m}$ to ensure proper alignment of the CIM features with the microchip element. An important component of this module is an air supply system that meters different volumes with controllable flow rates to seven different ports per channel that link to different chambers and channels to control the fluidic movements. The interaction between the CIM and the microchip is described below in microfluidic chip design.

Other instrument modules include: heating modules for liquid extraction and electrophoretic separation, detection laser and CCD assembly module, power and controller modules, IR laser modules to perform the IR laser mediated PCR, and high voltage modules to perform the electrophoretic separation. Each of these is designed to meet the specifications determined by either the microfluidic fluid flow or the molecular biological assays. Data analysis of the STR profiles is described in supplementary information. 


\subsection{Microfluidic chip design}

Previous work has shown that PCR and separation can be integrated for forensic STR analysis on a plastic microfluidic chip with the dimensions of a $96-w e l l$ plate ${ }^{35}$. The plastic microfluidic chip demonstrated here provides the fully integrated process of DNA liquid extraction, aliquoting a volume of the DNA extract, mixing with PCR reagents, PCR and electrophoretic separation with embedded electrodes - all within a completely enclosed disposable chip. Two critical dimensions from prior work ${ }^{35}$, the PCR chamber volume and effective separation length, were carried over to this design. The additional assay processes as well as reagent metering and mixing significantly increase the complexity of the microfluidic chip design. Therefore, the injection molded chip has features on both sides (top and bottom), creating two layers to achieve this additional functionality while retaining a minimal footprint. These two layers are a fluidic layer, containing many reagent storage reservoirs and transport channels, and an analytical layer, containing the PCR chamber and separation channel. The analytical layer also contains some transport channels by necessity of design. The design allows a simple manufacturing process capable of high volume production. This is described in more detail in the supplementary information (S.1 microfluidic chip fabrication).

Fig. 1c and Fig. 1d shows an overview of the chip design. Development of individual components of the design is discussed in the results section with respect to verifying functionality such as reagent mixing and DNA extract volume. Fig. 1c shows the top of the integrated microfluidic chip. Box 1 is a Luer lock connector that is injection molded as part of the chip for connecting the sample acceptor to it. Two heating plates, one on the inside CIM wall and one on the CIM door, contact the sample acceptors when the chip is inserted. Boxes 2 show 
electrode pads that pogo pins contact when the CIM top engages to physically contact the chip. There are four electrode pads per channel to transfer the voltage from the CIM to the electrophoresis reservoirs. Box 3 is the pneumatic interface region that allows fluids to move. The CIM top includes a silicon gasket that mates with this interface region. The pneumatic interface of the device is covered with a hydrophobic membrane to prevent liquid from contacting the CIM. The pneumatic system can deliver positive and negative pressures for fluidic movement. Box 4 is the detection region for one of the four channels where optics are aligned for sample detection. The detection optics are mounted on actuators that allow two-axes of motion for micrometer alignment precision. There are two pneumatic pistons per channel that can contact the chip for additional fluidic control by microfluidic valves (not highlighted).

Fig. 1d shows the integrated chip filled with dye to highlight each of the reagent reservoirs. The reservoirs and their volumes are given in Table 1 . The loading volumes are different because the filling lines from where the liquids are introduced into the chip are different for each of the reservoirs (the liquids are introduced from the filling ports highlighted by a red box in Fig. 1d). Four sample collectors were attached to this disposable consumable (Fig. 1b) and inserted in to the CIM (Fig. 1b). The instrument door is closed locking the chip inside and a main piston brings the CIM down in to contact with the chip. 
Table 1. Reagent volumes inside the microchip reservoirs and dye colors corresponding to each of them for identification in the Fig. 1d

\begin{tabular}{|c|c|c|}
\hline Reagent Reservoir & Color & Volume $(\boldsymbol{\mu l})$ \\
\hline ZyGEM extraction reagent & Blue & 200 \\
\hline PCR Mix \#1 & Red & 5.5 \\
\hline PCR Mix \#2 & Orange & 5.5 \\
\hline Separation reagents & Green & 17 \\
\hline Polymer & Purple & 20 \\
\hline
\end{tabular}

\subsection{Microfluidic chip loading}

The reagent reservoirs are filled by pipetting into the filling port of each reservoir (see the red box in Fig. 1d, 2 filling ports per reservoir, 8 in total per channel). Once the reagents are loading, the filling area is sealed with a PSA strip (Adhesives Research, Glen Rock, PA, USA). The separation polymer is loaded to the polymer reservoir to the right of the detection zone in Fig. 1d and is sealed with a pressure sensitive adhesive.

Microfluidic chip loading for a complete integrated run comprised the following steps: (1) adding a volume greater than $200 \mu \mathrm{L}$ to ensure complete filling of the reservoir and filling channels of the ZyGEM extraction reagents. A total of $900 \mu \mathrm{L}$ is prepared for 4 channels to allow extra volume for pipette errors: $846 \mu \mathrm{L}$ extraction buffer and $54 \mu \mathrm{L}$ EA1 enzyme based on prepGEM ${ }^{\mathrm{TM}}$ Saliva kit (ZyGEM corp., Hamilton, New Zealand). (2) $13 \mu \mathrm{L}$ of PCR reagents is used to fill both PCR reservoirs. PCR reagents are prepared with PowerPlex ${ }^{\circledR} 18$ Fast System Promega Corp., Madison, WI, USA), $69 \mu$ L Promega PowerPlex ${ }^{\circledR} 18$ Fast System primers, 35 
$\mu \mathrm{L}$ Promega PowerPlex ${ }^{\circledR} 18$ Fast System reaction mix and $6 \mu \mathrm{L}$ water. The Promega primer and reaction mix were modified by Promega for this specific PCR (based on the PowerPlex ${ }^{\circledR}$ 18D System $)^{36}$. (3) The separation reservoir is filled with $25 \mu \mathrm{L}$ of a separation reagent mix of $18 \mu \mathrm{L}$ Internal Lane Standard (ILS) 500 (Promega) and $90 \mu \mathrm{L}$ dilution buffer (Hi-DI ${ }^{\mathrm{TM}}$ Formamide, Life Technologies, Carlsbad, CA, USA) prepared for four channels. Finally, (4) $20 \mu \mathrm{L}$ hydrophobically-modified polyacrylamide polymer $^{35}$ (Microlab Diagnostics, Inc, VA, USA) containing DY-680 far red excitation dye (Dyomics GmbH, Jena, Germany) are introduced directly to the polymer reservoir.

For an allelic ladder separation, both PCR reservoirs are filled with water and $25 \mu \mathrm{L}$ separation reagents/allelic ladder mix is introduced into the separation reagent reservoir $\left(90 \mu \mathrm{L} \mathrm{Hi-DI}{ }^{\mathrm{TM}}\right.$ Formamide, $18 \mu \mathrm{L}$ Internal Lane Standard 500 and $25 \mu \mathrm{L}$ PowerPlex ${ }^{\circledR} 18 \mathrm{D}$ allelic ladder).

\subsection{Process optimization}

For each of the sub-assays (LE, PCR and ME), fluidic movement from one step to the next and sub-integration of LE-PCR and PCR-ME were tested to verify and optimize functionality. Fluidic movement tests were initially evaluated based on colorimetric results such as mixing and then verified with the assay result. For these sub-assay and sub-integration tests, only a portion of the microchip is loaded - the optimization approach here refers to the chip loading step numbers above.

For DNA extraction tests, only chip loading step (1) was introduced into the chip. This assay modifies the published protocol ${ }^{32}$ by reducing the enzyme activation time at $75{ }^{\circ} \mathrm{C}$ and deactivation time at $95{ }^{\circ} \mathrm{C}$ to 2 minutes each, the extraction is reduced to these unique two steps allowing PCR ready extract. Parameters such as enzyme activation time and mixing could then 
be varied compared to the recommended protocol for the prepGEM Saliva kit. Two DNA sources were tested: buccal swabs (MasterAmp ${ }^{\mathrm{TM}}$ Buccal Swab Brush, Epicentre, Madison, WI, USA) and FTA ${ }^{\mathrm{TM}}$ mini card (Indicating FTA ${ }^{\mathrm{TM}}$ Mini Card, Whatman Inc., Clifton, NJ, USA). Sample collection details can be found in supplementary information. Different sample sizes of FTA were tested for the optimization step $\left(25 \mathrm{~mm}^{2}, 50 \mathrm{~mm}^{2}, 75 \mathrm{~mm}^{2}, 100 \mathrm{~mm}^{2}\right.$ and $125 \mathrm{~mm}^{2}$ out of $490 \mathrm{~mm}^{2}$ for the entire FTA mini card circle). Four repeats were performed. These pieces were introduced into the $1 \mathrm{~mL}$ syringe attached to the chip and pushed toward the lower part (to be in contact with the LE heater).

For LE-PCR, (1) and (2) were loaded. PCR test chips filling is based on the PCR mix described for PCR-ME with an appropriate volume of DNA (extracted from benchtop extraction) corresponding to the aliquot portion within the mix. To verify the PCR-ME process, the same PCR mix was introduced into the PCR chamber. Reagents (3) and (4) are filled the same way than previously described. PCR and ME protocols are described in supplementary information.

In the system described here, the polymer is pneumatically loaded in to the microchannel by the instrument. As the polymer is loaded through the separation channel on the bottom layer of the chip and comes up through the vias, the liquid contacts the electrodes almost immediately upon entering the buffer and sample waste reservoirs resulting in connectivity between the electrodes. Additional polymer is pushed into these reservoirs to provide buffering capacity for electrophoresis. This optimization was done by observing initial connectivity over several chips and applying an additional time for polymer loading beyond this.

To assist with fluidic movement to the sample reservoir, the current between the sample electrode and the buffer electrode was monitored. As the sample electrode is located in the 
second half of the sample reservoir from where the sample enters, an increase in current between the sample and buffer electrodes provides an indicator for fluid flow. This is used as an active feedback sensor in the instrument control software for fluid flow to this reservoir. When adequate sample enters the sample reservoir and the increase in current is detected between the electrodes, the software stops the fluidic movement. When an inadequate volume of fluid is in the sample reservoir and there is no change in current, an additional fluidic movement is prompted by the software.

\section{Results}

\subsection{Extraction optimization}

The microfluidic chip contains the extraction reagents which become fluidically connected to the sample acceptor when the pneumatic module pushes the ZyGEM reagent from one port into the sample collector as shown in Fig. 2a (blue dyed reagents into the collector for all four channels). The instrument door and the CIM contain contact heaters (red in Fig 2a) that clamp the sample collector to raise the sample to the ZyGEM enzyme activation and denaturation temperatures (in this picture, the door is open so that chip and sample collectors can be seen). As shown in the image, the ZyGEM reagent covers approximately two-thirds of the swab so that an additional benchtop extraction can be performed after microchip analysis if desired. Following the LE, the solution is drawn back into the ZyGEM reservoir.

DNA was extracted from two different sources - a brush buccal swab and FTA paper. The extraction protocol was first optimized for a buccal swab. Initial extractions pumped the liquid extraction reagents into the sample acceptor, heated the solution to the target activation and denaturation temperatures, and drew the solution out of the sample acceptor. This "Simple Flow" 
protocol resulted in an average DNA yield of $2.5 \mathrm{ng} / \mu \mathrm{l}$ (Fig. 2b), which is below the yield that will produce full STR profiles in microchip PCR amplifications. Longer extraction times were tested but did not increase the yield (Fig. S.2).

Mixing after the denaturation step was tested to determine if a higher DNA yield will be obtained when extract is pumped in and out of the sample acceptor. Doing so increased the yield by fivefold and the yield was flow rate dependent with slower mixing $(\sim 3.5 \mu 1 / \mathrm{sec})$ yielding 6.0 $\mathrm{ng} / \mu \mathrm{l}$ and faster mixing (approximately $15 \mu \mathrm{l} / \mathrm{sec}$ in and $30 \mu \mathrm{l} / \mathrm{sec}$ out) yielding $9.0 \mathrm{ng} / \mu \mathrm{l}$. In the final protocol, the syringe compression rate was set to $50 \mu \mathrm{l} / \mathrm{sec}$ which yielded a fluid flow rate of approximately $20 \mu \mathrm{l} / \mathrm{sec}$. The difference in syringe rate and fluid flow rate is due to compressibility of air and air flow restrictions in the instrument between the syringe and the chip. The fluid flow rate is the critical factor and therefore is the factor that is the primary interest for development.

FTA paper optimization began with trying different punch sizes of FTA mini cards (as described in 2.4) inside the sample acceptor and performing the same LE protocol as buccal swab with mixing. The PCR-ready extracts from the two smallest FTA punches did not give full conventional profiles indicating insufficient DNA yield. The largest FTA punches gave full conventional profiles but the FTA paper absorbed too much liquid to be able to draw back a sufficient amount to have liquid proximal to the aliquot line and this would have resulted to a failure for LE-PCR on chip. The $100 \mathrm{~mm}^{2}$ FTA paper pieces were able to give full conventional profiles and the amount of liquid absorbed was acceptable for the aliquot step, with a small modification of the fluid flow script taking the absorbed liquid into account. Confirmatory tests were done with 20 samples of $100 \mathrm{~mm}^{2}$ FTA paper punches in parallel with 20 samples of buccal brush swab to allow direct comparison (4 donors repeated 5 times). The extracted DNA was then 
quantified using Quantifiler® Duo DNA Quantification kit (Life Technologies). The yield from the FTA paper was found to be lower than the buccal swabs for some of the data points (Fig. 2c). However inhibition in the qPCR assay was observed for some of these samples, which may have resulted in this reduction. Moreover, the sample recovery and sample collection process difference can lead to variability in the results. The graph also shows that the DNA yield from the FTA paper can be as high as that obtained by buccal swabs (for example points around 10 $\mu \mathrm{L} / \mathrm{ng}$ ) when only $100 \mathrm{~mm}^{2}$ of the FTA paper is put into the system compared to a buccal swab. More importantly, despite the difference in DNA yield, all samples from both the FTA paper and buccal swabs samples gave full profiles using the PowerPlex ${ }^{\circledR} 18$ Fast System on a conventional PCR system (See representative full profiles in Fig. S.3a and b). Analysis of these full profiles shows that the PCR quality from both methods is comparable. Assuming that the height of each peak reflects the number of copies of the microsatellite present in the DNA (i.e. DNA concentration for PCR), Fig. S.3c and S.3d show that the DNA concentration used for PCR from both methods were comparable since the peak heights fall within the same range for all the samples. The Powerplex 18 PCR did not appear to suffer the inhibition seen in some qPCR results. Moreover, the peak height ratio is greater than 50\% for almost all of the samples (Fig. S.3e) although buccal swabs peak height values are a little lower for some of the samples. The LE extracts from both sample types were able to provide extracted DNA samples yielding balanced multiplexed PCR for human identification and 100\% full profiles.

\subsection{PCR and LE-PCR optimization}

Microchip PCR has been previously demonstrated on a simpler microchip that required the preparation of ZyGEM DNA and mixing of reagents outside the chip ${ }^{35}$. Therefore the first step to achieve LE-PCR is to demonstrate that a DNA aliquot, with the target yield, can be 
microfluidically mixed with PCR reagents and flowed in to the PCR chamber. An aliquot is taken by drawing the extract from the ZyGEM reservoir toward the hydrophobic membrane as shown by the red arrows in Fig. 3a. The aliquot volume is defined by the microchannel dimensions between the hydrophobic membrane port (blue dot formed by the liquid stopped at the membrane) and the active valve (oval with two vias in the middle). The active valve is then actuated after the aliquot is taken. To prevent PCR reagents being drawn toward the hydrophobic membrane, surface tension valves are placed on either side of the PCR reservoirs.

The aliquot is then pushed off the hydrophobic membrane toward the PCR reagent mixing chamber through the PCR reagents chambers (Fig. 3b). The DNA aliquot begins mixing with the PCR reagents during the movement to the mixing chamber. The mixing chamber spans the depth of the injection molded piece $(1.5 \mathrm{~mm})$ so it can be connected to both layers: the reagents enter the mixing chamber on the bottom layer and a vent line on the top layer on the opposite side of the chamber allows air to vent. Air is pushed into the chamber after the PCR reagents and DNA sample and bubbles through the liquid to the top of the chamber and vents out of the microchip through a pneumatic port. Colorimetric tests indicate good mixing within this chamber (Fig. 3b).

During the fluidic movement to the mixing chamber, the active valve downstream of the PCR chamber was closed. This valve is then allowed to open and PCR mix is pushed from the mixing chamber to the PCR chamber (Fig. 3c). The channel exiting the mixing chamber toward the PCR chamber is on the bottom layer to reduce the probability of bubbles being pushed in to this channel. Once the PCR chamber is filled, the active valve downstream of the PCR chamber is closed. The PCR chamber is then pressurized to 5 PSI against the active valve to prevent bubble formation and liquid movement during PCR. 
In preliminary studies, the impact of DNA mass in the PCR chamber on PCR peak heights was investigated. It was found that when DNA mass falls below $1.2 \mathrm{ng}$ in the PCR chamber, peak heights begin to decrease below the target threshold of $1000 \mathrm{RFU}$ on a conventional $\mathrm{CE}$ instrument. With an average DNA yield of $9.0 \mathrm{ng} / \mu 1$, and a lower standard deviation bound of 6 $\mathrm{ng} / \mu \mathrm{l}$, the aliquot microchannel volume was designed to hold $4 \mu \mathrm{l}$. This volume provides an average DNA mass of $2.4 \mathrm{ng}$ with a lower standard deviation of $1.6 \mathrm{ng}$.

The microfluidic movement and mixing efficiency during LE-PCR were verified by comparing integrated results with a microchip amplification where the DNA extraction and reagent mixing steps were performed off-chip. Fig. 3d and 3e show LE-PCR from a buccal swab and FTA paper, respectively. Each method produced a full profile (18-loci) with similar peak balances and similar peak heights (with variations due to sample to sample variation, amount of unreacted master mix pulled from the chip with the sample...) to each other and to profiles obtained with PCR on chip (off-chip mixing). These LE-PCR tests demonstrated that the microchip fluidic control is capable of generating sufficient DNA, drawing an aliquot of the extracted DNA, mixing with the PCR reagents, and filling the PCR chamber without bubbles.

\subsection{Automated Alignment}

The separation channels have a width of $50 \mu \mathrm{m}$ and therefore the detection sensitivity is expected to have a low tolerance to variations in chip-to-chip alignment. Fig. 4a (bars) shows the standard deviation of the alignment position for 19 chips. This variation in microchannel position from one chip to the next is then compared with the change in detection sensitivity to alignment position. Fig. S.4 shows that to maintain $80 \%$ of the maximum signal, the allowable deviation in the Y-axis and Z-axis is approximately $10 \mu \mathrm{m}$ and $38 \mu \mathrm{m}$, respectively. The lines in Fig. 4a represent this allowable deviation. While the Z-axis conforms to this threshold for three out of 
four channels, the Y-axis is well above maximum allowable deviation. Therefore, an automated alignment method for every chip is required to detect the fluorescent DNA. To achieve this, a high wavelength dye, outside of the dye spectrum used for the DNA, was added to the separation buffer. This dye is excited and collected by the same laser induced fluorescence system as for the STR DNA fragments. The optics system rasters the focusing and collecting lenses in the Y-axis with step changes in the Z-axis (focusing axis) between lateral scans. The high wavelength dye signal is maximized to find the separation channel. Fig. $\mathbf{4 b}$ shows a representative trace of the high wavelength dye signal during the alignment procedure with the fitting curve to identify to optimal alignment point.

\subsection{ME and PCR-ME Optimization}

Prior to ME, the polymer reservoirs are pressurized to 30 PSI (see Fig. 5a for the air movement with the red arrows) to push the polymer through the separation channels to each of the buffer, sample and sample waste electrodes. This loading pressure was applied for 30 minutes in addition to connectivity time to allow excess polymer to provide buffing capacity the buffer and sample waste electrodes for stable electrophoresis current during the entire separation. This polymer loading step was performed during the PCR in the PCR-ME and the full integrated runs.

ME in a plastic microchip were demonstrated on a simpler device were the polymer was loaded manually ${ }^{35}$. To verify that ME performed similarly to that previous simpler design, an allelic ladder was separated after fluid flow from separation reservoir. Voltages were adjusted to keep similar field strength to those used in the previous study. In order to validate the ME, the allelic ladder and separation reagents were mixed and introduced directly into the sample reservoir. The ME is able to resolve all of the peaks in the ladder to generate a binning matrix (Fig 5b). TH01 
9.3 and 10 are resolved that demonstrate that the system is able to discriminate the single base pair required by the forensic community for that multiplex kit (Fig. 5b left bottom corner).

Integration of the PCR and ME was tested to verify mixing of the PCR product with the separation reagents. Following PCR thermocycling pressurized PCR chamber is purged slowly and the active valves are opened. Separation buffer is pushed through the PCR chamber into the separation sample reservoir with current assist as described in Section 2.4. The arrows in Fig. 5c show the fluidic movement. At this point, the stage is heated to the separation temperature for ME. Fig. 5d shows a typical integrated PCR-ME test for the 18-plex PCR amplification. Both the PCR products and ILS ladder are detected verifying sufficient mixing of the two liquids and good injection, separation and detection of all fragments, the good mixing shown here was consistent with colorimetric tests. The allele calls in the profiles were compared with the conventional analysis performed for the same donor to verify correct allele calling (always found to be concordant).

\subsection{Integrated LE-PCR-ME}

Following the successful demonstration of LE-PCR and PCR-ME partial integration, microchip LE-PCR-ME is tested. Buccal swabs were loaded into the sample acceptors and attached to a chip loaded into the instrument. The complete full end-to-end integrated process is then run on the device leading to a genetic profile analyzed by GeneMarker ${ }^{\mathrm{TM}}$ and compared with the conventional reference profiles for concordance.

LE-PCR-ME analyses of buccal swabs are shown in Fig. 6. Three different donors were tested for this preliminary demonstration of the fully integrated microfluidic chip for "sample in-answer out" human identification (Fig.6 a-c). The profiles show each of the 18 loci were successfully 
amplified and separated with the internal lane standard. The alleles from the sample were analyzed using GeneMarker ${ }^{\mathrm{TM}}$ to call the allele numbers using a binning palette created from an allelic ladder separation run on the system under the same condition. The allele calling was compared against the conventional method and found to be $100 \%$ correct for each of the sample.

Fig. 6 c-d shows the same donor analyzed three times by the end-to-end microchip demonstrating that the system is capable of reproducing the same profile. Therefore, full and concordant genetic profiles can be obtained by LE-PCR-ME on the microfluidic chip demonstrated here.

\section{Discussion}

The advantages of a fully integrated $\mu$ TAS for forensic STR analysis are clear: (i) a fully enclosed microfluidic system reduces the opportunity for contamination from conventional liquid transfer steps, (ii) a simple work flow allows less experienced users to perform the analysis at the point of sample collection, and (iii) the analysis time is reduced substantially compared with the current process. While the sample-to-answer analytical time is reduced, the greater impact of these systems may be the time-savings of eliminating the need to send the samples to a central laboratory for testing.

Other integrated DNA systems have been previously reported ${ }^{28,29,31}$, it is important to note several critical features that distinguish the system described here. First, the main component of the microchip is a single injection molded piece of Cyclo Olefin Polymer (COP). This significantly reduces the cost of a fabrication compared with devices made from glass ${ }^{28}$ or from multiple components ${ }^{29,30 .}$ The final microchip assembly processes of sputtering electrodes, solvent bonding and lamination of the capping layers on to the flat chip are well-established and 
can be easily scaled to larger batches of microchips. This straightforward fabrication process, along with no requirement for microchip surface pretreatment, enables a simple and low-cost fabrication process.

Second, this microchip has the footprint roughly the size of a 96-well plate and is capable of analyzing four samples. This is a stark contrast to other reports for assays that achieve high resolution separation by using a much larger microchip, or that require an interface to a capillary for the separation. The reduced size is enabled by two different technologies First, the unique hydrophobically-modified polyacrylamide polymer enable the high resolution DNA separation to be achieved in an effective length of $7 \mathrm{~cm}$ compared with other reports for similar assays with lengths of $22.5 \mathrm{~cm}$ in a plastic substrate ${ }^{31}, 14 \mathrm{~cm}$ in a glass substrate ${ }^{28}$, or in a one the shelf capillary $^{29}$. Second, the ZyGEM enzyme preparation method allows footprint compression through reduction in the number of reagents, fewer fluidic transport channels, and no reservoir for liquid waste (e.g., adsorption and wash buffers for solid phase extraction).

The microchip design also allows easy recovery of both the amplified product and the extracted DNA if additional post-assay processing if desired. The ZyGEM extraction method leaves the excess DNA in an easily recoverable solution rather than in a waste reservoir. The Luer lock connector design allows different DNA sources to be input in to the system for analysis increasing the flexibility of the design for different assays. While this study focused of forensic applications, the DNA preparation - PCR amplification - electrophoretic separation process is used in other diagnostics including, clinical, environmental and food testing. 


\section{Conclusions}

A fully integrated sample-in-answer-out microchip for human identification base on STR analysis was demonstrated. A combination of enzymatic DNA preparation, microliter PCR, and a unique separation polymer enabled a compact footprint, plastic microchip substrate, and eliminated all surface pretreatment. The enzymatic DNA preparation with appropriate microfluidic movements lead to full genetic profiles from buccal brush swabs and buccal cells on FTA paper that show the system can be used for at least two different DNA inputs. An aliquot of this DNA sample allowed an 18-plex STR amplification that provides similar profiles to the conventional method. The PCR product was separated in an effective length of $7 \mathrm{~cm}$ using a polymer that is demonstrated to resolve each of the peaks of the allelic ladder and achieved concordant and accurate allele calling for three different individuals. This proof-of-concept micro-total analysis system is a critical step towards achieving a low cost microchip for a pointof-collection human identification system.

\section{Acknowledgements}

The authors are grateful for the technical support of Michael E. Egan, Darren Albert, Douglas J. South from Lockheed Martin Corp, Bethesda, MD. We also thank Doug Storts from Promega Corporation, for reagents improvements and supporting the development and Morpho for financial support. Finally, the authors are especially grateful to the collaboration with Minifab, Victoria, Australia for microfluidic chip design development and fabrication. 


\section{References}

1. P.-A. Auroux, Y. Koc, A. deMello, A. Manz, and P. J. R. Day, Lab. Chip, 2004, 4, 534-546.

2. P. Lisowski and P. K. Zarzycki, Chromatographia, 2013, 76, 1201-1214.

3. A. K. Yetisen, M. S. Akram, and C. R. Lowe, Lab. Chip, 2013, 13, 2210-2251.

4. M. Mascini and S. Tombelli, Biomark. Biochem. Indic. Expo. Response Susceptibility Chem., 2008, 13, 637-657.

5. D. Eicher and C. A. Merten, Expert Rev. Mol. Diagn., 2011, 11, 505-519.

6. L. Kulinsky, Z. Noroozi, and M. Madou, Methods Mol. Biol. Clifton NJ, 2013, 949, 3-23.

7. D. Mark, S. Haeberle, G. Roth, F. von Stetten, and R. Zengerle, Chem. Soc. Rev., 2010, 39, 1153-1182.

8. Y. Zhang and P. Ozdemir, Anal. Chim. Acta, 2009, 638, 115-125.

9. C. W. Price, D. C. Leslie, and J. P. Landers, Lab Chip, 2009, 9, 2484-2494.

10. D. Wu, J. Qin, and B. Lin, J. Chromatogr. A, 2008, 1184, 542-559.

11. M. C. Breadmore, K. A. Wolfe, I. G. Arcibal, W. K. Leung, D. Dickson, B. C. Giordano, M. E. Power, J. P. Ferrance, S. H. Feldman, P. M. Norris, and J. P. Landers, Anal. Chem., 2003, 75, 1880-1886.

12. D. Jungkind, J. Clin. Virol. Off. Publ. Pan Am. Soc. Clin. Virol., 2001, 20, 1-6.

13. R. J. Mariella, Biomed. Microdevices, 2008, 10, 777-784.

14. A. J. de Mello and N. Beard, Lab. Chip, 2003, 3, 11N-20N.

15. E. A. Oblath, W. H. Henley, J. P. Alarie, and J. M. Ramsey, Lab. Chip, 2013, 13, 1325-1332.

16. I. Pjescic and N. Crews, Lab. Chip, 2012, 12, 2514-2519.

17. D. Chen, M. Mauk, X. Qiu, C. Liu, J. Kim, S. Ramprasad, S. Ongagna, W. R. Abrams, D. Malamud, P. L. A. M. Corstjens, and H. H. Bau, Biomed. Microdevices, 2010, 12, 705-719.

18. S. Nie, W. H. Henley, S. E. Miller, H. Zhang, K. M. Mayer, P. J. Dennis, E. A. Oblath, J. P. Alarie, Y. Wu, F. G. Oppenheim, F. F. Little, A. Z. Uluer, P. Wang, J. M. Ramsey, and D. R. Walt, Lab. Chip, 2014, 14, 1087-1098.

19. A. F. Sauer-Budge, P. Mirer, A. Chatterjee, C. M. Klapperich, D. Chargin, and A. Sharon, Lab. Chip, 2009, 9, 2803-2810.

20. K.-Y. Lien, C.-J. Liu, P.-L. Kuo, and G.-B. Lee, Anal. Chem., 2009, 81, 4502-4509.

21. Z. Chen, W. R. Abrams, E. Geva, C. J. de Dood, J. M. González, H. J. Tanke, R. S. Niedbala, P. Zhou, D. Malamud, and P. L. A. M. Corstjens, BioMed Res. Int., 2013, 2013, 543294.

22. X. Pan, L. Jiang, K. Liu, B. Lin, and J. Qin, Anal. Chim. Acta, 2010, 674, 110-115.

23. B. S. Ferguson, S. F. Buchsbaum, T.-T. Wu, K. Hsieh, Y. Xiao, R. Sun, and H. T. Soh, J. Am. Chem. Soc., 2011, 133, 9129-9135.

24. R. H. Liu, J. Yang, R. Lenigk, J. Bonanno, and P. Grodzinski, Anal. Chem., 2004, 76, 18241831.

25. J. M. Butler, Fundamentals of Forensic DNA Typing, Elsevier Science, 2009.

26. K. M. Horsman, J. M. Bienvenue, K. R. Blasier, and J. P. Landers, J. Forensic Sci., 2007, 52, 784-799.

27. C. J. Easley, J. M. Karlinsey, J. M. Bienvenue, L. A. Legendre, M. G. Roper, S. H. Feldman, M. A. Hughes, E. L. Hewlett, T. J. Merkel, J. P. Ferrance, and J. P. Landers, Proc. Natl. Acad. Sci., 2006, 103, 19272-19277.

28. P. Liu, X. Li, S. A. Greenspoon, J. R. Scherer, and R. A. Mathies, Lab Chip, 2011, 11, 10411048. 
29. L. K. Hennessy, H. Franklin, Y. Li, J. Buscaino, K. Chear, J. Gass, N. Mehendale, S. Williams, S. Jovanovich, D. Harris, K. Elliott, and W. Nielsen, Forensic Sci. Int. Genet. Suppl. Ser., 2013, 4, $7-8$.

30. A. J. Hopwood, C. Hurth, J. Yang, Z. Cai, N. Moran, J. G. Lee-Edghill, A. Nordquist, R. Lenigk, M. D. Estes, J. P. Haley, C. R. McAlister, X. Chen, C. Brooks, S. Smith, K. Elliott, P. Koumi, F. Zenhausern, and G. Tully, Anal. Chem., 2010, 82, 6991-6999.

31. E. Tan, R. S. Turingan, C. Hogan, S. Vasantgadkar, L. Palombo, J. W. Schumm, and R. F. Selden, Investig. Genet., 2013, 4:16.

32. D. Moss, S. A. Harbison, and D. J. Saul, Int. J. Legal Med., 2003, 117, 340-349.

33. J. A. Lounsbury, N. Coult, D. C. Miranian, S. M. Cronk, D. M. Haverstick, P. Kinnon, D. J. Saul, and J. P. Landers, Forensic Sci. Int. Genet., 2012, 6, 607-615.

34. M. G. Roper, C. J. Easley, L. A. Legendre, J. A. C. Humphrey, and J. P. Landers, Anal. Chem., 2007, 79, 1294-1300.

35. D. Le Roux, B. E. Root, C. R. Reedy, J. A. Hickey, O. N. Scott, J. M. Bienvenue, J. P. Landers, L Chassagne, and P. De Mazancourt, Anal. Chem., 2014, (submitted).

36. K. Oostdik, J. French, D. Yet, B. Smalling, C. Nolde, P. M. Vallone, E. L. R. Butts, C. R. Hill, M. C. Kline, T. Rinta, A. M. Gerow, S. R. Allen, C. K. Huber, J. Teske, B. Krenke, M. Ensenberger, P. Fulmer, and C. Sprecher, Forensic Sci. Int. Genet., 2013, 7, 129-135. 


\section{Figures:}

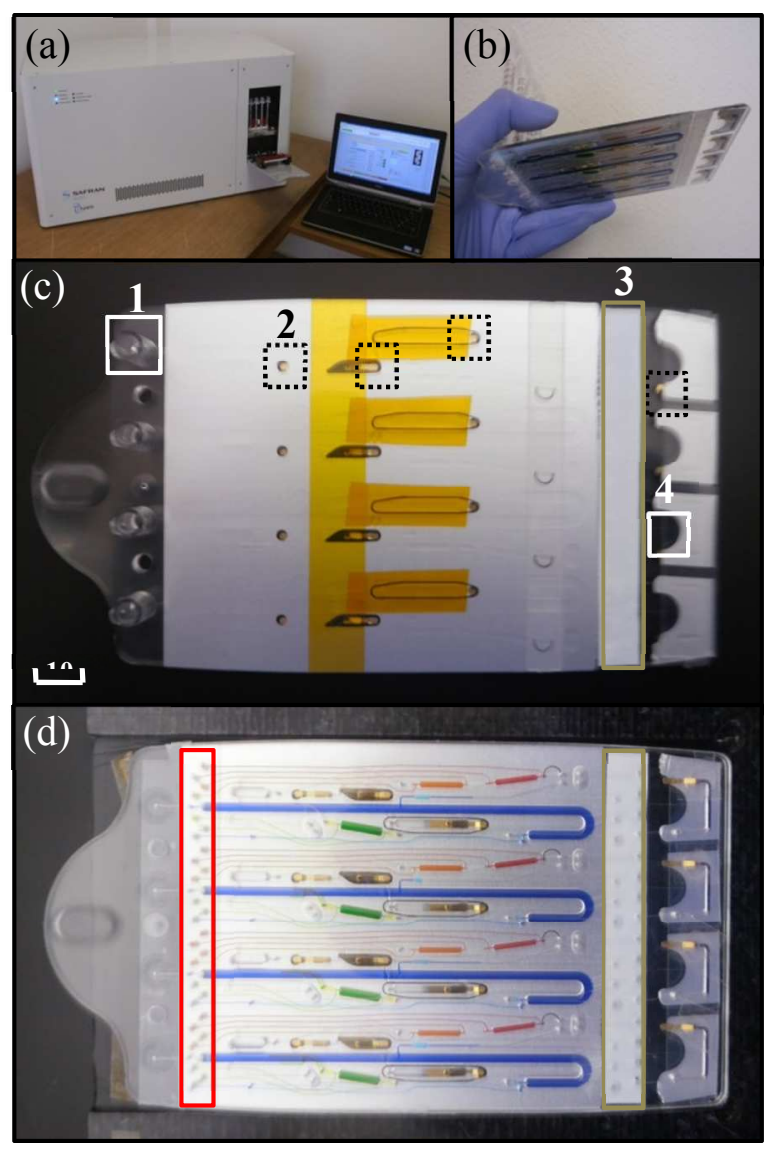

Fig. 1. Microfluidic chip and instrument. (a) Chip inside the instrument with swabs attached and computer containing the software that. (b) View of the microchip with swabs attached to it in a gloved hand, note the thickness. (c) Top view of the microchip containing (1) 4 sample acceptors, (2) 4 electrode pads per channel, (3) a pneumatic interface with 7 air ports per channel and (4) four detection regions. (d) Bottom view of the chip containing the fluidic layout with blue reagents in the ZyGEM reagent reservoir, red and orange in the PCR reagent reservoirs, green reagents in the separation reservoir and polymer in the polymer reservoir (reservoirs in the right connected to the electrode pads). The red box highlights the filling area (two ports per reservoir) and the brown box highlights the pneumatic airports below the hydrophobic membrane. 

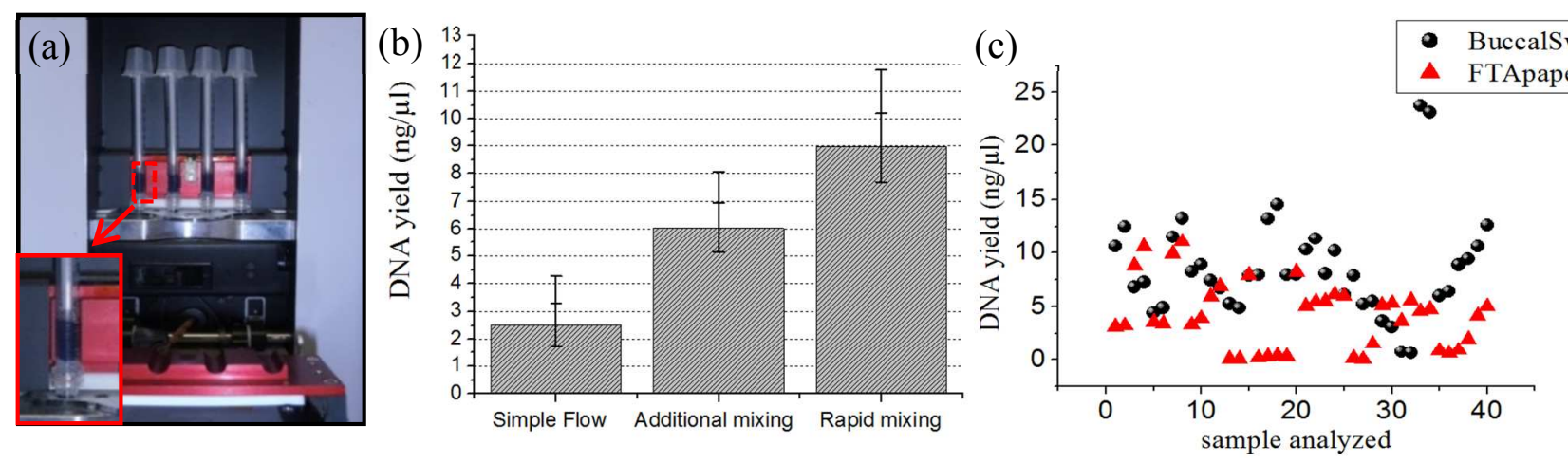

Fig. 2. Liquid Extraction on chip (LE). (a) Microchip inside the instrument with swabs submerged by blue reagents, LE is occuring inside the sample acceptor tubes. (b) This figure shows the DNA yield from the LE microchip based on different fluid flow protocols to increase DNA yield $(n=5)$. Simple flow is when ZyGEM extraction mix is pushed in to the syringe, heating occurs, and the fluid is simply drawn back in to the microchip. Additional Mixing and Rapid Mixing refer to additional fluid flow movements into and out-of the syringe after LE heating at different rates. (c) FTA paper DNA yield compared to brush swab DNA yield with the same LE protocol on the device (20 samples for each of DNA source), duplicate quantification for each of the sample with Quantifiler® Duo DNA Quantification kit (Life Technologies). 

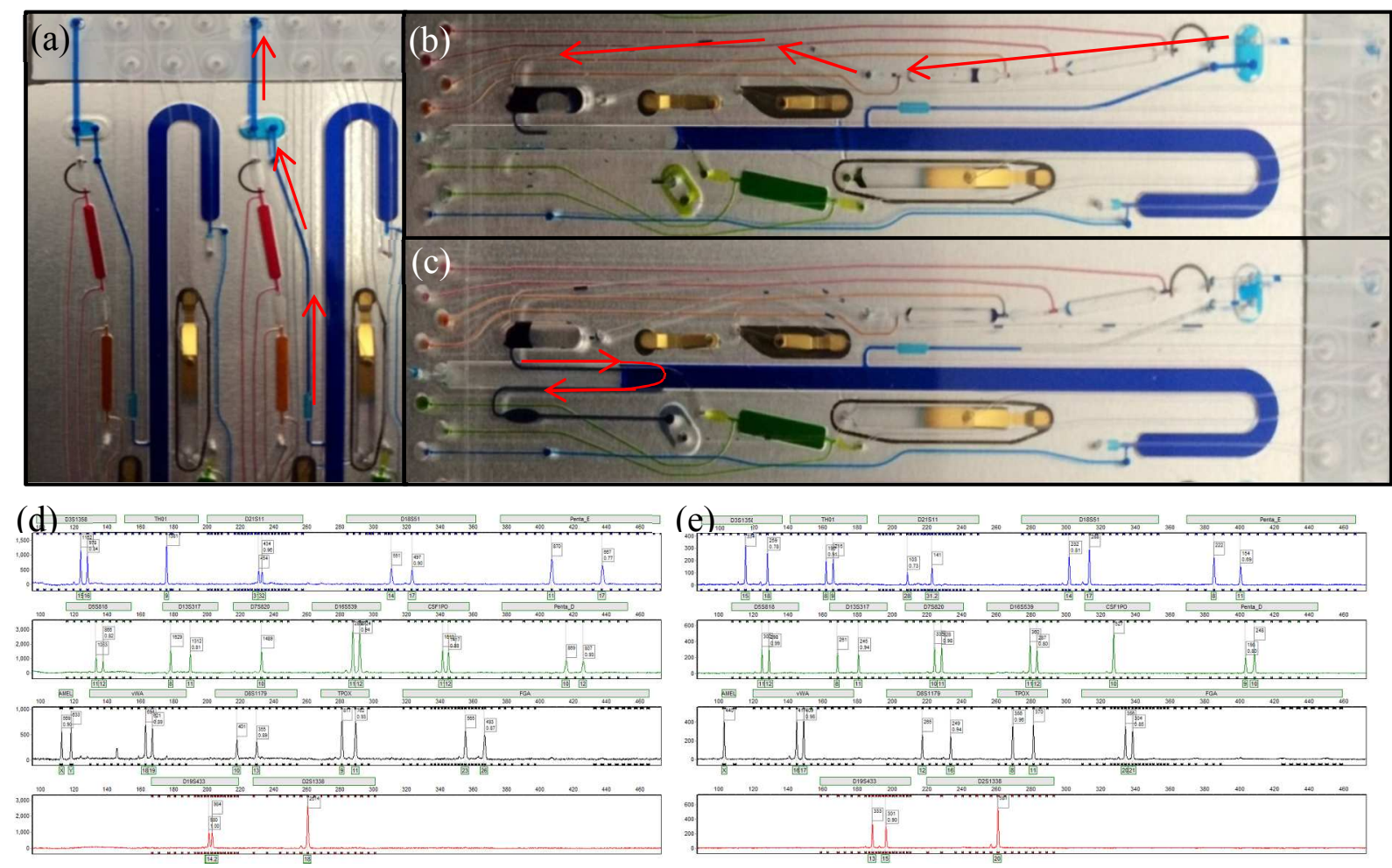

Fig. 3. LE-PCR optimization. (a) PCR ready-LE DNA aliquot drawn back from the ZyGEM reservoir toward the hydrophobic membrane. (b) Aliquot pushed toward the mixing chamber (red circle) through the PCR reagent reservoirs. (c) PCR chamber filled by the PCR mix pushed toward the active valve stopped at it. Eelectropherograms from conventional ABI $310 \mathrm{CE}$ instrument of (d) a LE-PCR on chip from a buccal swab and (e) a LE-PCR on chip from a 100 $\mathrm{mm}^{2}$ FTA paper piece. 


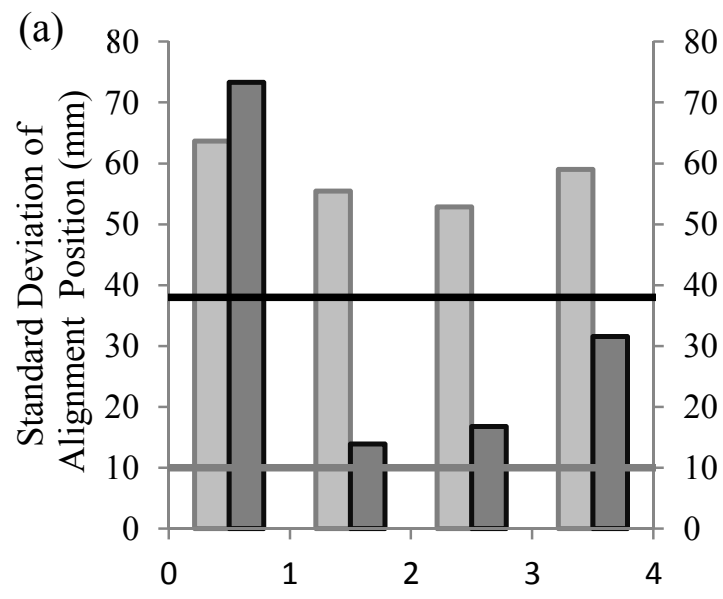

Channel Number

$\square$ Y-Axis Alignment Standard Deviation

ZZ-Axis Alignment Standard Deviation

—Y-Axis Maximum Allowable Alignment Deviation

-Z-Axis Maximum Allowable Alignment

(b) Deviation

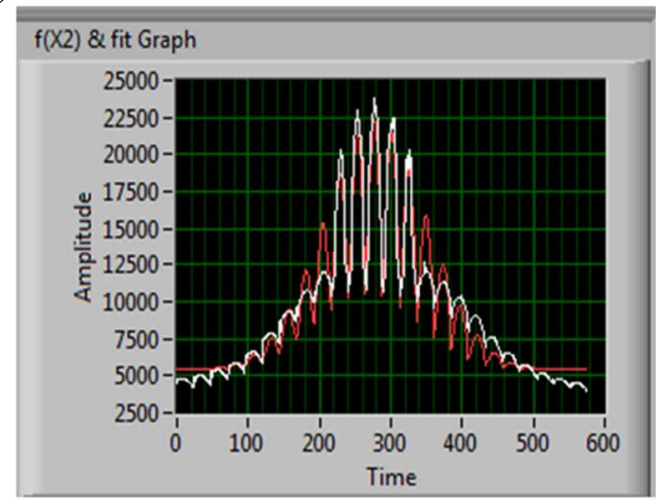

Fig. 4. Automated alignment. (a) Standard deviation of channel alignment position over 19 microchips for the $\mathrm{Y}$ - and Z-axis for each channel (bars) compared with the maximum allowable alignment deviation for to maintain $80 \%$ of the maximum signal (lines). (b) Example automated alignment result in which the optics are rastered in the Y-axis an incrementally moved in the Zdirection around the expected alignment position. The graph gives the fluorescence intensity of the high wavelength dye over the time of the scan (white line) and a line from a fitting algorithm (red line) that determines the correct alignment position. 


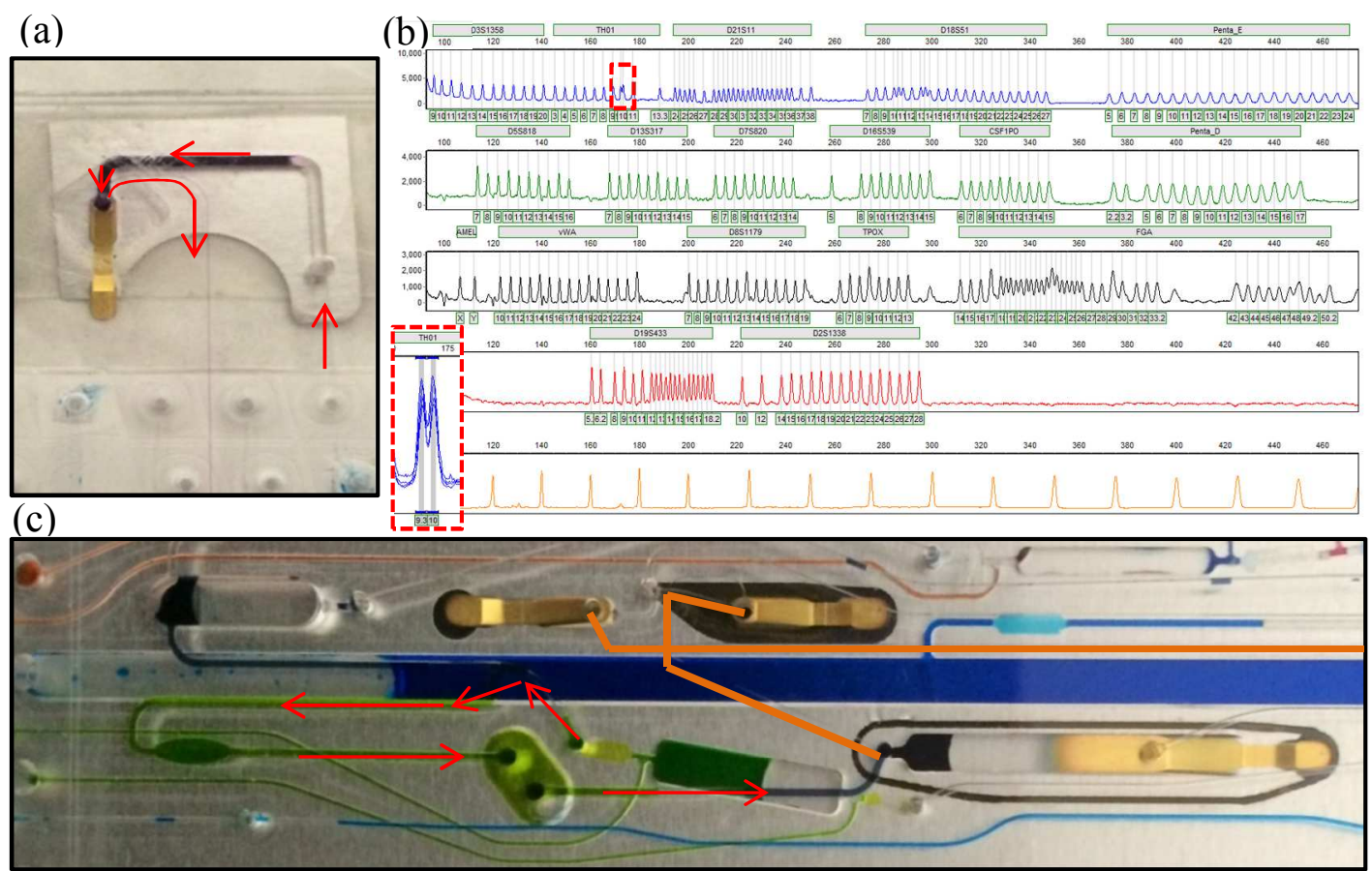

(d)
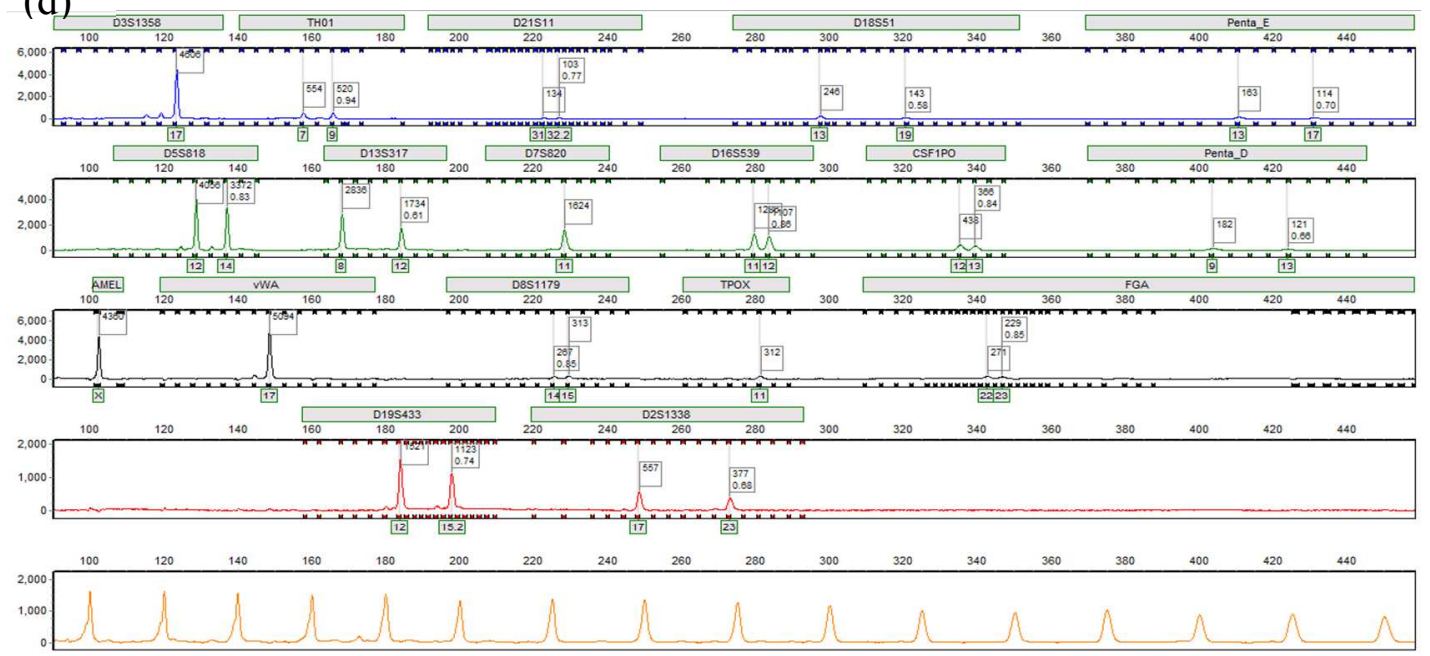

Fig. 5. PCR-ME optimization. (a) Polymer filling the microchip electrophoresis. (b) Electropherogram from an allelic ladder separation in the 7-cm microchip channel with five examples of 9.3-10 alleles for TH01 marker showing the one base pair resolution (expanded in red box). (c) Separation reagents going through the PCR chamber toward the sample reservoir, flushing the PCR products, red arrows show the fluidic movement, the PCR product mixed with 
the separation reagents are then ready to be electrophoretically separated (cross $\mathrm{T}$ injection and separation microchannel showed in orange). (d) A PCR-ME performed inside the microfluidic chip. The Internal Lane Standard is well separated aswell as the DNA peaks.

(a)
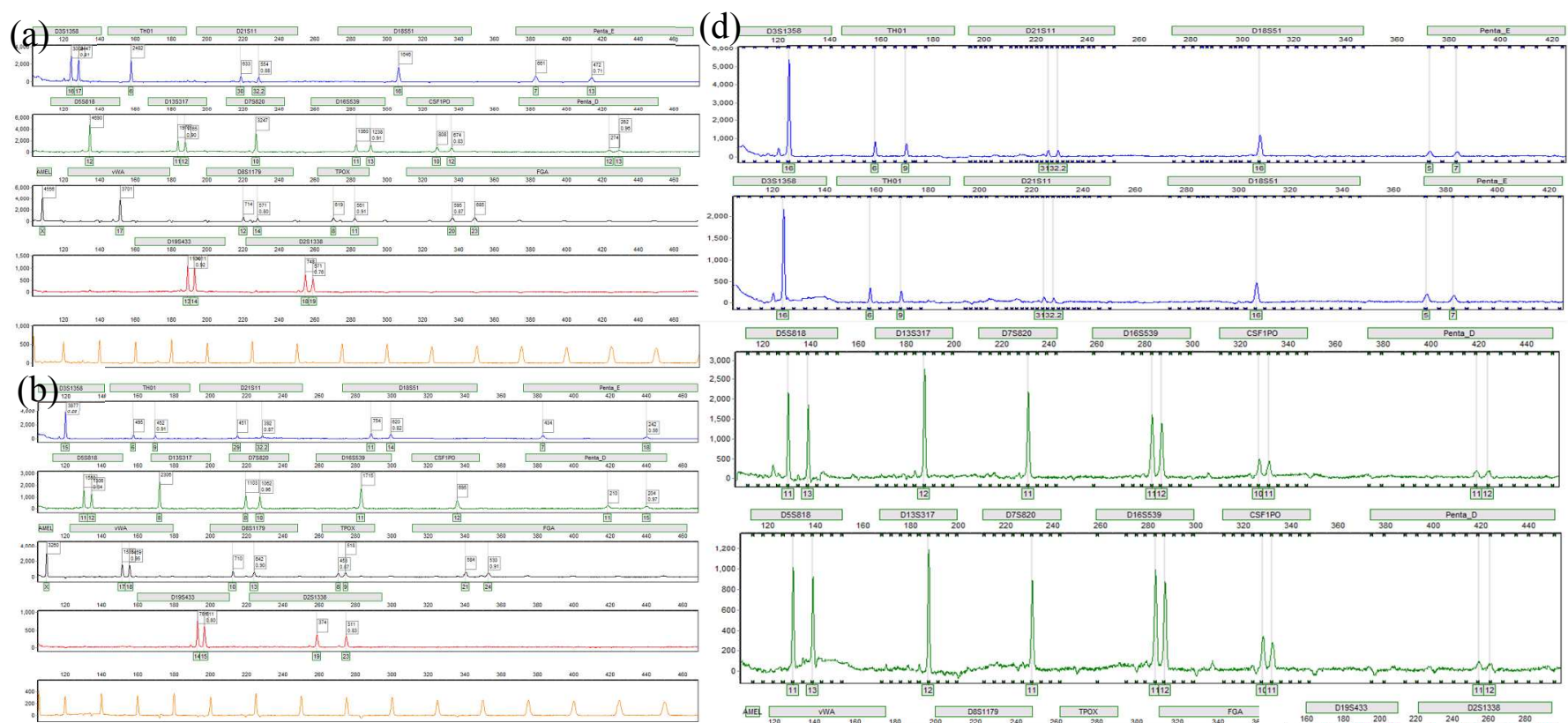

(C)
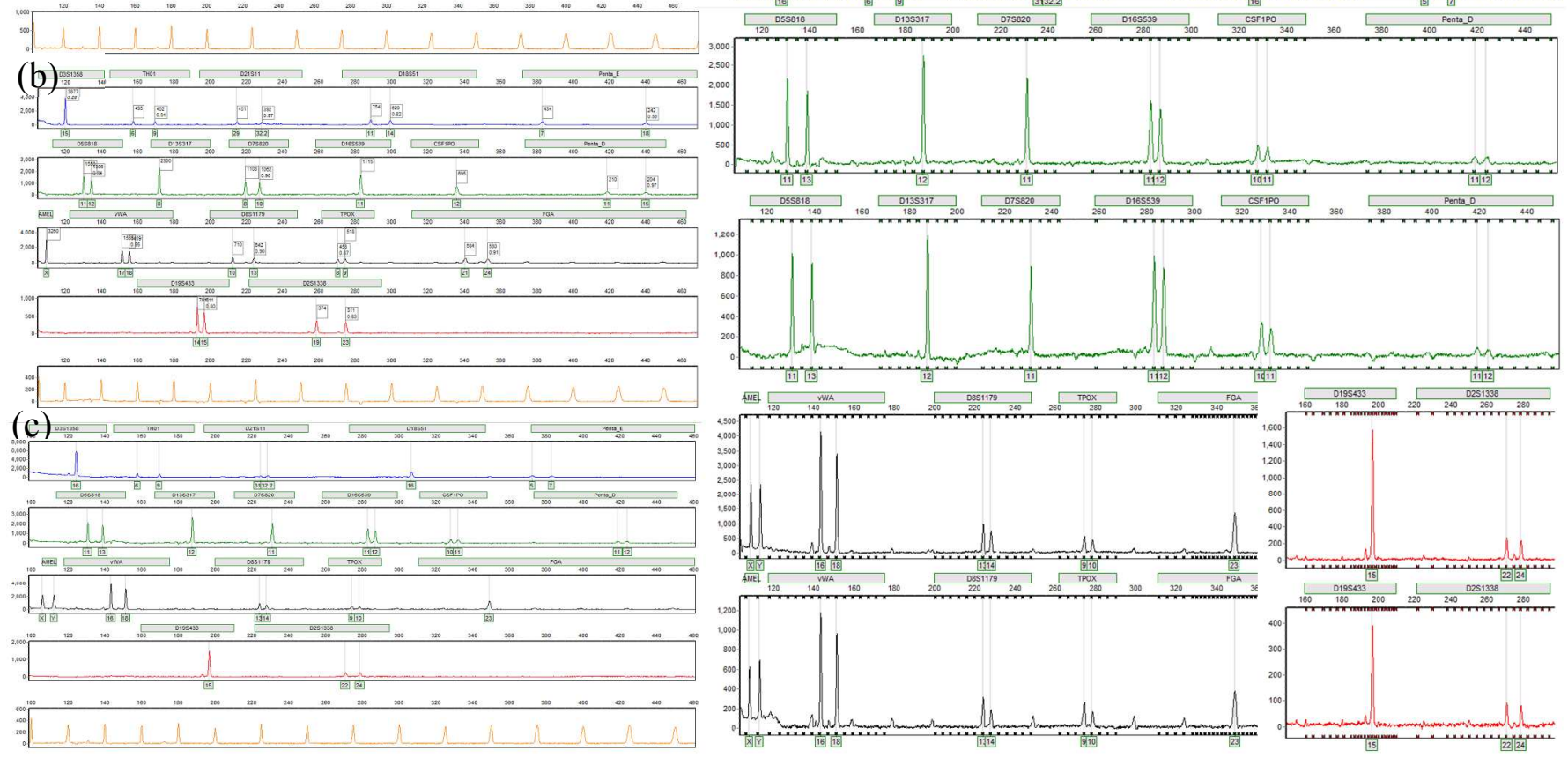

Fig. 6. Sample-in-answer-out integrated LE-PCR-ME on microchip. (a), (b) and (c) are results from three different DNA donors. The fully integrated runs gave concordant full profiles comparable to conventional results. (d) Representation of two integrated LE-PCR-ME from the same donor showing two full profiles, the dye color markers are shown together to highlight the similarity between both genetic profiles. 


\section{Lab on a Chip}

Supplementary Information

\section{Integrated sample-in-answer-out microfluidic chip for Rapid Human Identification by STR analysis}

\section{Table of Contents}

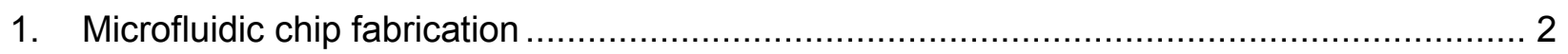

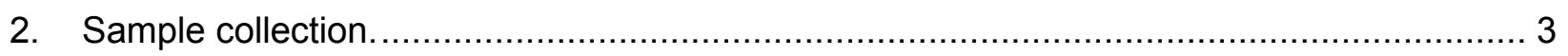

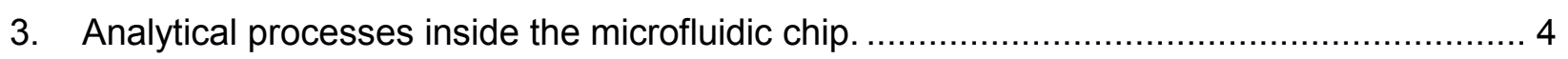

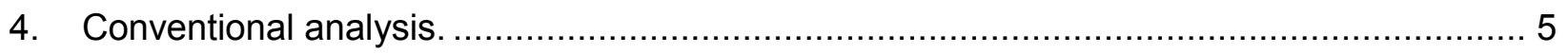

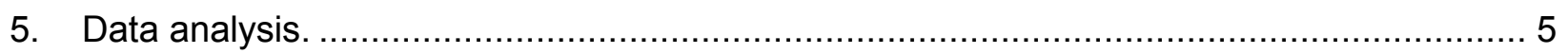

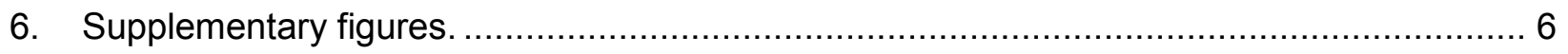

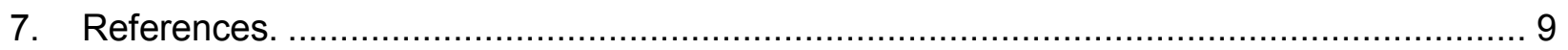




\section{Microfluidic chip fabrication}

The microfluidic chips were fabricated by MiniFAB Pty Ltd (Scoresby, Australia). The chip was injection molded out of Zeonor 1420R (Zeon Chemicals, Louisville, KY, USA) with microfluidic features on both molding inserts (Fig. S.1a and S.1b). ZEONOR ${ }^{\circledR}$ is a Cyclo Olefin Polymer (COP) that have become widely used in the microfluidic device designs due to biocompatibility and optical properties. ${ }^{1}$

The microfeatures on both molding inserts create a single injection molded piece with microfluidic features on two layers that can complete all aspects of the assay. A $100 \mu \mathrm{m}$ film of the same material was solvent bonded to the bottom side of the microchips (Fig. S.1c). The bottom side of the chip contains the separation channel, PCR chamber and several fluidic transport channels (Fig.S.1d). Next, gold is sputtered from the top side to create the electrodes for electrophoretic separation. Electrodes were sputtered to a thickness of approximately $100 \mathrm{~nm}$. The pneumatic interface region is layered with a double-sided adhesive, AR90445 (Adhesives Research, Glen Rock, PA, USA), with laser cut holes that aligned to the ports in the molded microfluidic chip. Hydrophobic membrane (PTFE, 0.2 micron, SterliTech, Kent, WA, USA), was then placed over the adhesive to form the pneumatic interface region (Fig. S.1e).

A top laminate was an aluminum-acrylic laminate composite and was laser cut to the dimensions of the chip and with several critical features. Two perforated lines were created that align both sides of the pneumatic interface region (Fig. 1c). This allowed the top film to be laminated as a single piece yet allowing an easy peel action just prior to reveal the protected hydrophobic membrane (from debris, scratch etc). Cutouts in this layer were created for the detection zone and around the sample waste electrode. A track outlining the sample reservoir was also created to further isolate that electrode as the acrylate layer may not provide a perfect 
insulating boundary and in some cases allow resistance on the order of the separation channel (1$10 \mathrm{M} \Omega$ ) causing current leakage. These cutouts and tracks around the electrodes served to reduce this possible failure mode. Polyimide tape (McMaster Carr, Elmhurst, IL, USA) was placed over these cutouts and tracks to ensure that liquid was contained within the microchip. A cap was placed over the luer connectors until the chip was used to prevent contamination or debris from entering this feature. This assembled chip was then ready for reagent loading (Fig. S.1f).

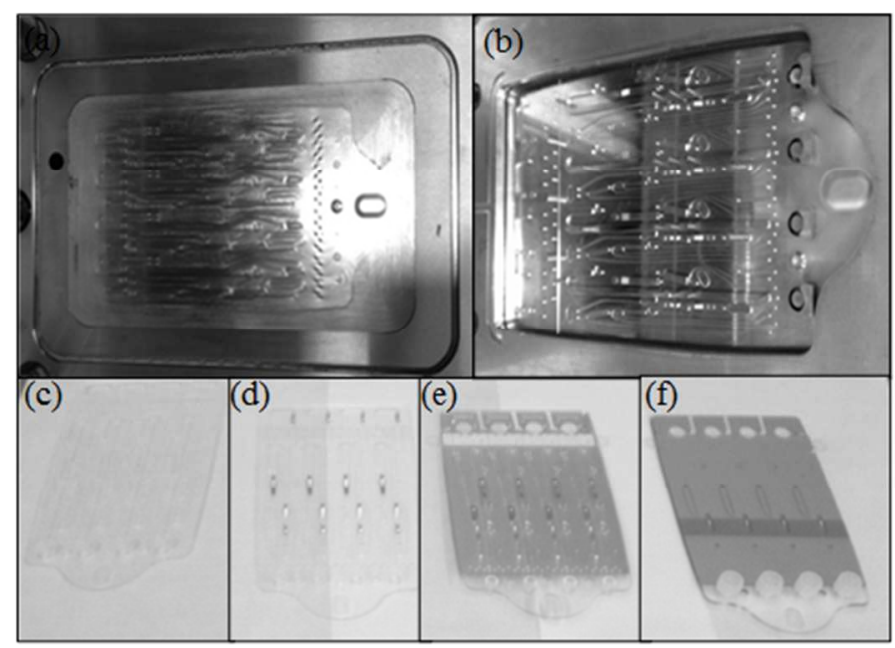

Fig. S.1. Microfluidic chip manufacture process. (a) Picture of the bottom molding part of the insert. (b) Picture of the top molding bottom part. (c) Chip after injection mold and bottom layer bond. (d) Chip after gold sputtering. (e) Chip after different aluminum-acrylic composite and hydrophobic membrane layers bonding. (f) Chip after polyimide tape and luers cap addition.

\section{Sample collection.}

Buccal cells were collected after a 30 seconds mouth rinsing in both cases, by turning the buccal brush swabs against the cheek for 30 seconds and using a DNA collector for FTA ${ }^{\mathrm{TM}}$ (sterile foamtipped applicator, Puritan Medical Products Company LLC, Guilford, ME, USA) after putting it 
against the tongue for 30 seconds to moisturize it and scrub each of the cheeks with each of the side of the collector. The buccal swab was directly put into the swab acceptor attached to the chip. The DNA collector was applied onto one circle of the FTA mini card to get the maximum of cells.

\section{Analytical processes inside the microfluidic chip.}

Microchip PCR is accomplished by IR-heating and non-contact temperature sensing as described in Le Roux et $a l^{2}$. Based on these results, the thermocycling conditions were an initial denature of $94{ }^{\circ} \mathrm{C}$ for one minute, 29 cycles of $94{ }^{\circ} \mathrm{C}$ for 10 seconds and $59{ }^{\circ} \mathrm{C}$ for 40 seconds, and a final extension of $59{ }^{\circ} \mathrm{C}$ for 2 minutes. Compared with the previous report ${ }^{2}$, these conditions increase the number of cycles from 27 to 29 and slightly increase the length of the anneal and denature times to increase peak heights. The increased in peak heights with longer anneal and denature times may be a function of differences in thermal mass between the two systems causing a difference in heating and cooling ramp rates.

Microchip electrophoresis for STR analysis was previously demonstrated in a $7 \mathrm{~cm}$ effective separation length following a standard cross-T injection method. The microchip used the same effective separation length but with different channel lengths from the cross- $T$ node to the electrodes. The voltage drop along each arm was kept between the two designs requiring different applied voltages. The sample was electrokinetically injected by applying $300 \mathrm{~V}$ at the sample waste with the sample electrode grounded for $360 \mathrm{sec}$. A 6 second gated injection was used with $1500 \mathrm{~V}$ at the outlet and the sample electrode again grounded. The separation was performed with $1500 \mathrm{~V}$ on the outlet electrode, $250 \mathrm{~V}$ and $300 \mathrm{~V}$ on the sample and sample 
waste electrode, respectively, and the buffer electrode grounded. The stage heater temperature that controlled the separation polymer temperature within the microchip channel was set to $43^{\circ} \mathrm{C}$.

To test automated alignment of the system, the separation channel was loaded in the same manner as for an end-to-end sample analysis. The sample reservoir was loaded with a fluorescein solution. The channel was aligned as normal by maximizing the signal of the alignment dye. To determine the change in signal with alignment position, the fluorescence intensity is measured when no fluorescein is in the channel and when fluorescein is electrophoresed to the detection zone. The signal is taken as the difference in intensity and the noise is taken as the standard deviation of the fluorescence intensity when no fluorescein is present in the channel. The alignment actuators are then moved in the $\mathrm{Y}$ - or Z-direction away from the optimal alignment position and the measurement is taken again.

\section{Conventional analysis.}

Liquid Extraction/PCR and Capillary Electrophoresis are performed to compare the results of some sub-assays on the microfluidic chip following the manufacturer's instructions and using a GeneAmp® PCR System 9700 thermal cycler (Life Technologies, Carlsbad, CA, USA), a ABI PRISM® 310 Genetic Analyzer (Life Technologies) and a ABI PRISM® 3130Avant Genetic Analyzer (Life Technologies).

\section{Data analysis.}

Data analysis from both microfluidic and conventional processes was performed with SoftGenetics GeneMarker® HID v2.4.0 software (SoftGenetics, LLC, State College, PA, USA). 
The microfluidic platform performed the data processing of the assay using proprietary software (Lockheed Martin Corp., Bethesda, MD, USA) that interfaced with GeneMarker®.

\section{Supplementary figures.}

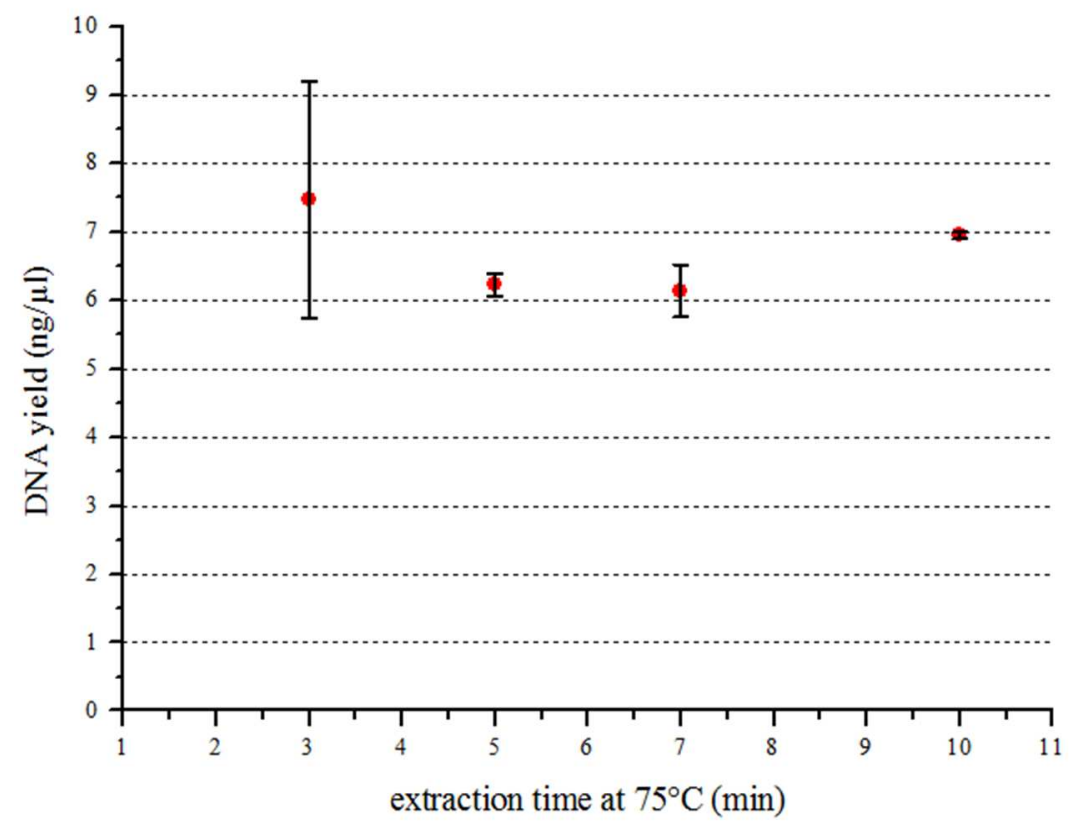

Fig. S.2. DNA yield from ZyGEM extractions on chip with increasing amounts of extraction time (i.e. time at $75^{\circ} \mathrm{C}$ ). $\mathrm{n}=3$. 
(a)

(b)
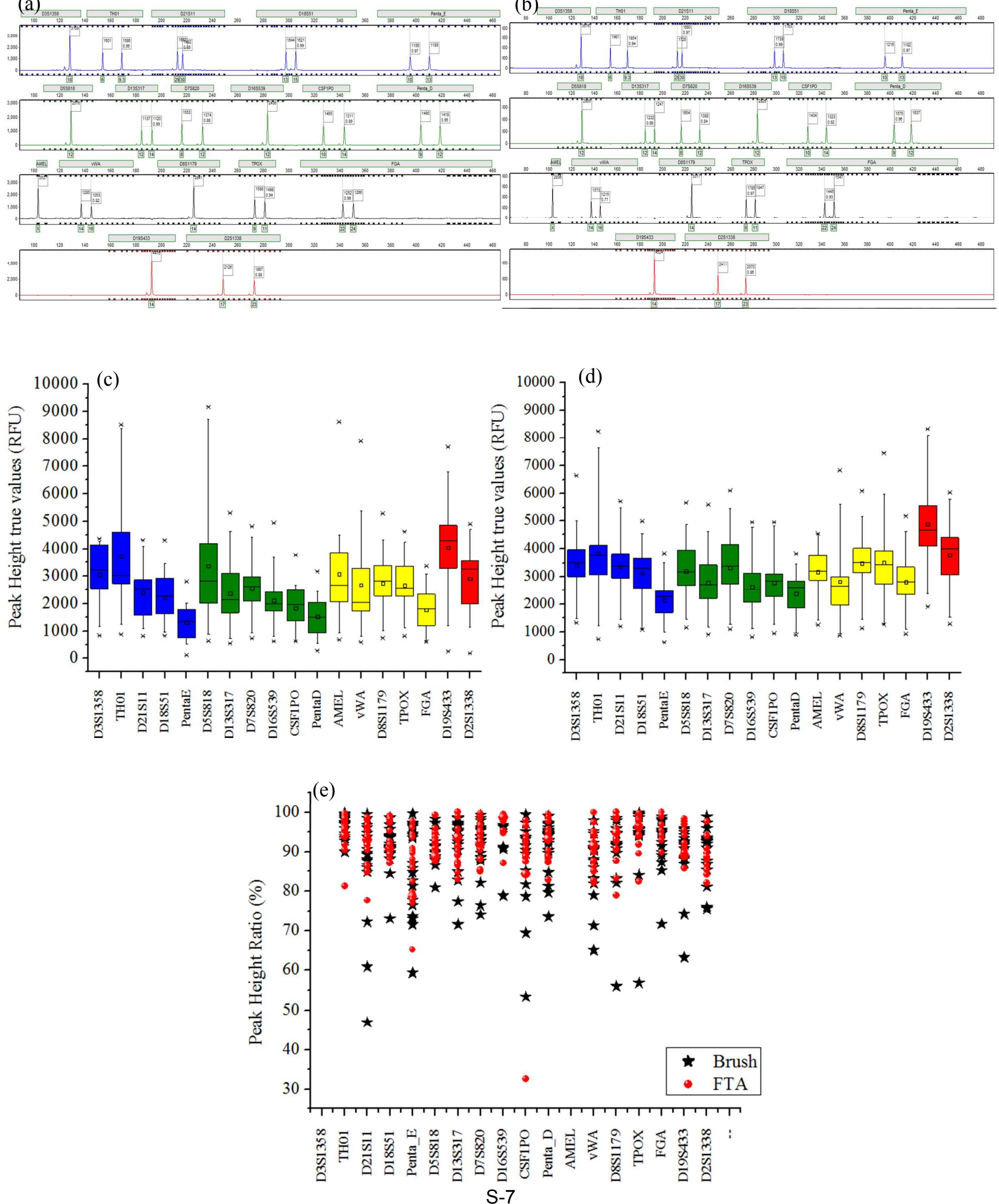
Fig. S.3. Results from LE of buccal brush swab and FTA paper followed by conventional buccal swab extracted inside the instrument (LE on chip), (b) Electrophoregram from a $150 \mathrm{~mm}^{2}$ FTA paper piece from the same donor extracted inside the instrument. Conventional results from the buccal swabs and FTA paper (20 samples for each DNA source) (c to e). (c) Box plot of the peak height true values from the buccal brush swabs (sum of heterozygote peak heights divided by two or homozygous peak heights divided by two). (d) Box plot of the peak height true values from the FTA paper. (e) Peak height ratio characterizing PCR from buccal swabs and FTA (Higher peak height divided by smaller peak height for heterozygous alleles).

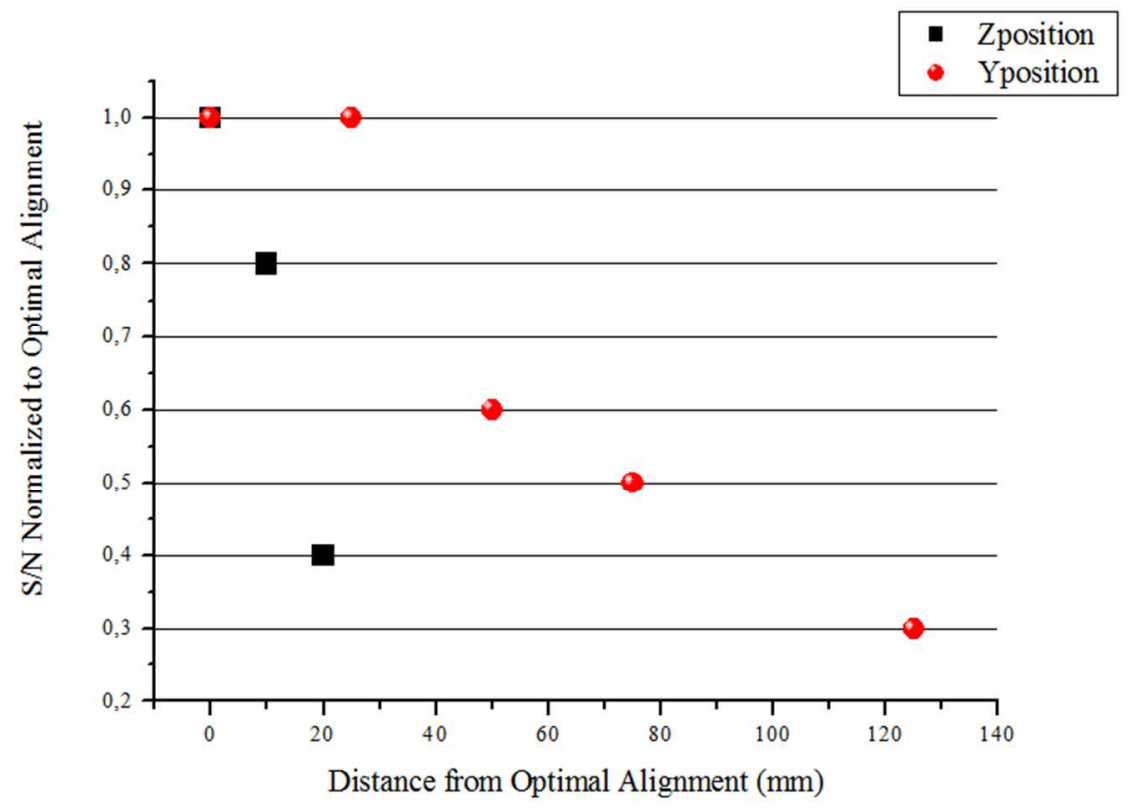

Fig. S.4. Tolerance of sensitivity to misalignment in the X-and Z-directions. The optics were positioned to maximize the signal from fluorescein the buffer that was loaded in to the channel. The actuators were then moved set distances in the $\mathrm{X}$ - and Z-directions. The signal was calculated from the difference in pixel intensity of when the fluorescein was present in the 
channel versus a channel with only buffer. The noise was calculated as the standard deviation in signal intensity when no fluorescein is present.

\section{References.}

1. K. Liu and Z. H. Fan, Analyst, 2011, 136, 1288-1297.

2. D. Le Roux, B. E. Root, C. R. Reedy, J. A. Hickey, O. N. Scott, J. M. Bienvenue, J. P. Landers, L. Chassagne, and P. De Mazancourt, Anal. Chem., 2014, (submitted). 